\title{
Analysis of load sharing behavior for piled rafts using normalized load response model
}

\author{
Donggyu Park ${ }^{\text {i) }}$ Doohyun Kyung ${ }^{\text {i) }}$, Daesung Park ${ }^{\text {ii) }}$ Incheol Kim $^{\text {i) }}$ and Junhwan Lee ${ }^{\text {iii) }}$ \\ i) Ph.D. candidate, School of Civil and Environmental Engineering, 50, Yonsei-Ro, Yonsei University, Seoul, 120-749, Korea \\ ii) Graduate research assistant, School of Civil and Environmental Engineering, 50, Yonsei-Ro, Yonsei University, Seoul, 120-749,Korea \\ iii) Professor, School of Civil and Environmental Engineering, 50, Yonsei-Ro, Yonsei University, Seoul, 120-749, Korea
}

\begin{abstract}
In the conventional pile design, pile cap is regarded as a structural member that connects the superstructure and piles, transferring imposed loads to the lower foundation parts. The load carrying capacity of pile cap is not in general taken into account even for direct contact condition with ground surface. In the present study, the load carrying behaviors of piled rafts are investigated focusing on the individual load-settlement responses of piles and raft on piled rafts. A settlement-based load sharing model for piled rafts is proposed using the normalized non-linear load-settlement relationship with consideration of piled-raft interaction effect. According to the proposed load sharing model, the load sharing ratio $\alpha_{\mathrm{p}}$ decreases as settlement increases with rates depending on the load capacity ratio. The values of $\alpha_{\mathrm{p}}$ are higher for higher load capacity ratios. To check the validity of the proposed load sharing model, centrifuge load tests are conducted. The values of $\alpha_{p}$ calculated from the proposed load sharing model are in close agreement with measured values.
\end{abstract}

Keywords: piled rafts, load sharing behavior, hyperbolic model, centrifuge tests, normalized load-settlement curves

\section{INTRODUCTION}

The behavior of piled rafts is complex because of the combined nature of raft and piles that behave as a unit producing various interaction effects between foundation components and surrounding soils. The load response and load carrying capacity of piled rafts have been investigated experimentally and analytically using various testing methods and numerical analyses (Randolph 1994, Reul and Randolph 2004, Conte et al. 2003, Katzenbach et al. 2005, Giretti 2010).

Key component for the design of piled rafts is the load sharing phenomenon that occurs between raft and piles. Majority of investigations on the load sharing behavior of piled rafts has been done introducing and considering foundation stiffness and geometry conditions of raft and piles (Clancy and Randolph 1996, Sanctis and Mandolini 2006). As the load carrying capacity of foundation may change with settlement, it is desired to establish a certain correlation or design model that represents the load sharing behavior according to settlement. The non-linearity in the load response of piled rafts and the interaction effect also need to be addressed for the assessment of the load sharing behavior.

In this paper, the load sharing behavior of piled rafts is investigated using a non-linear normalized load sharing model that reflects the non-linear, state-dependent load response of piled rafts. For this purpose, a hyperbolically-defined normalized loadsettlement relationship for piled rafts is introduced to describe the combined load responses of raft and piles. The normalized load-settlement relationship is used to develop the load sharing model for piled rafts where the settlement-dependent variation of load sharing behavior is taken into account. The results from centrifuge load tests are presented for various model foundations and used to compare with those from the non-linear load sharing model.

\section{LOAD RESPONSES OF PILED RAFTS}

Piled rafts represent a complex load response and load carrying behavior due to the combined nature of different structural components and interactions between foundations and surrounding soils. For piled rafts, the load carrying capacity is composed of those from raft and piles:

$$
Q_{p r}=Q_{r}+Q_{p}=Q_{r}+\sum Q_{p i}
$$

where $\mathrm{Q}_{\mathrm{pr}}=$ load carrying capacity of piled raft; $\mathrm{Q}_{\mathrm{r}}$ and $\mathrm{Q}_{\mathrm{p}}=$ load carrying capacities of raft and piles; and $\mathrm{Q}_{\mathrm{pi}}=$ load carrying capacity of individual pile.

The load sharing behavior can be described using the load sharing ratio that represents the ratio of load carried by piles to load imposed on piled raft as follows: 


$$
\alpha_{p}=\frac{Q_{p}}{Q_{p r}}=\frac{Q_{p}}{Q_{r}+Q_{p}}=1-\frac{Q_{r}}{Q_{p r}}
$$

where $\alpha_{p}=$ load sharing ratio; $Q_{p r}=$ load imposed on piled raft; $Q_{r}$ and $Q_{p}=$ loads carried by raft and piles. According to Clancy and Randolph (1996), $\alpha_{p}$ can be obtained using stiffness of raft and piles using a correlation given as follows:

$$
\alpha_{p}=1-\frac{\left(1-i_{r p}\right)\left(k_{r} / k_{p}\right)}{1+\left(1-2 i_{r p}\right)\left(k_{r} / k_{p}\right)}
$$

where $\mathrm{k}_{\mathrm{r}}$ and $\mathrm{k}_{\mathrm{p}}=$ individual stiffness of raft and piles on load-settlement curves; and $i_{\mathrm{rp}}=$ raft-pile interaction factor with the upper limit equal to 0.85 .

As the values of tolerable settlement differ for different foundation types and target design levels, it is important to properly identify and consider the variation of $\alpha_{p}$ with settlement into the design of piled rafts. The soil type is also a factor that affects the behavior of piled rafts and load sharing ratio. When the load sharing and load carrying behavior are analyzed for piled rafts, therefore, the soil type needs to be clearly specified and considered in the analysis.

\section{LOAD SHARING MODEL}

\subsection{Normalized Load-Settlement Relationship}

The hyperbolically defined load-displacement relationship has been popular in various geotechnical problems and long been used to describe the non-linear load responses of foundations. Following the hyperbolic function first proposed by Kondner (1963), the non-linear load-settlement relationship can be written as the following relationship:

$$
Q=\frac{s}{a+b \cdot s}
$$

where $\mathrm{Q}=$ load; $\mathrm{s}=$ settlement; and $\mathrm{a}$ and $\mathrm{b}=$ hyperbolic parameters. Note that raft and piles are different in their size and thus the scale of load capacity. This indicates that the load-settlement relationship of Eq. (4) represents an individual load response of foundation component and the combined load response of piled rafts cannot be expressed in a single formulation of Eq. (4).

As geometrical and mechanical characteristics of raft and piles are different, the load-settlement relationship was normalized in terms of relative settlement and load using foundation size and ultimate load capacity, respectively (Lee et al., 2014). Modifying and normalizing Eq. (4) with the ultimate load capacity and raft width, the following relationship is obtained:

$$
\frac{Q_{r}}{Q_{r, u}}=\frac{s / B_{r}}{a_{r}+b_{r} \cdot\left(s / B_{r}\right)}
$$

where $\mathrm{Q}_{\mathrm{r}}=$ load imposed on raft; $\mathrm{Q}_{\mathrm{r}, \mathrm{u}}=$ ultimate load capacity of raft; $s=$ settlement; $B_{r}=$ raft width; and $a_{r}$ and $b_{r}=$ model parameters for the normalized hyperbolic load-settlement relationship of raft. For piles, similarly, the normalized load-settlement relationship can be obtained as follows:

$$
\frac{Q_{p}}{Q_{p, u}}=\frac{s / B_{p}}{a_{p}+b_{p} \cdot\left(s / B_{p}\right)}
$$

where $\mathrm{Q}_{\mathrm{p}}=$ load imposed on piles; $\mathrm{Q}_{\mathrm{p}, \mathrm{u}}=$ ultimate load capacity of piles; $s=$ settlement; $B_{p}=$ pile diameter; and $a_{p}$ and $b_{p}=$ model parameters for normalized hyperbolic load-settlement relationship for piles.

\subsection{Normalized Load Sharing Ratio Model}

Eqs. (5) and (6) both represent the dimensionless, normalized relationships. This implies that it is possible to directly combine the equations for describing the load responses of piled rafts. Combining and modifying Eqs. (5) and (6), the load sharing ratio $\alpha_{p}$ of Eq. (2) with settlement can be obtained as follows:

$$
\alpha_{p}=\frac{1}{\left(\frac{Q_{r, u}}{Q_{p, u}}\right)\left[\frac{a_{p} \cdot \lambda_{B}+b_{p} \cdot\left(s / B_{r}\right)}{a_{r}+b_{r} \cdot\left(s / B_{r}\right)}\right]+1}
$$

where $\mathrm{Q}_{\mathrm{r}, \mathrm{u}}$ and $\mathrm{Q}_{\mathrm{p}, \mathrm{u}}=$ ultimate load capacities of raft and piles; $\lambda_{\mathrm{B}}=$ foundation size ratio $=\mathrm{B}_{\mathrm{p}} / \mathrm{B}_{\mathrm{r}}$; and $\mathrm{a}_{\mathrm{r}}, \mathrm{b}_{\mathrm{r}}$, $a_{p}$, and $b_{p}=$ model parameters for normalized relationship.

Owing to the normalized characteristics of Eqs. (5), (6) and(7), the normalized load-settlement relationships and load sharing model are applicable to various foundation conditions. It should be however noted that the values of ultimate load capacities of each foundation component become different depending on foundation and soil conditions.

\section{CENTRIFUGE LOAD TESTS}

\subsection{Testing Program}

Centrifuge load tests were conducted using various model foundations and used to compare with the results from the normalized load sharing model. The centrifuge acceleration applied in this study was $60 \mathrm{~g}$ and all the model foundations were fabricated at the model scale of $1 / 60$. Three different types of model foundations were adopted in the tests, including unpiled raft, group piles, and piled raft. The piles were made of aluminum with diameter and length equal to 0.01 and $0.25 \mathrm{~m}$, respectively. These correspond to diameter and length equal to 0.6 and $15 \mathrm{~m}$ in prototype scale, respectively. 16 piles were used for group piles and piled raft in a $4 \times 4$ square configuration with pile spacing distance equal to $2.4 \mathrm{~m}$ corresponding to 4 times pile diameter of $0.6 \mathrm{~m}$ (i.e., $4 \mathrm{~B}_{\mathrm{p}}$ ). The raft was made of aluminum and 
square shaped with width equal to $0.15 \mathrm{~m}$ corresponding to $9 \mathrm{~m}$ in prototype scale. The piled raft was instrumented in order to separately measure the load responses of raft and pile components and to obtain decomposed load-settlement curves.

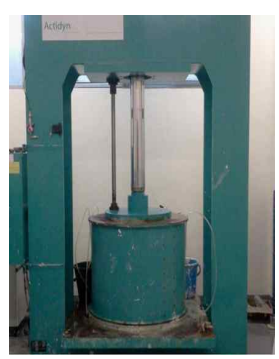

(a)

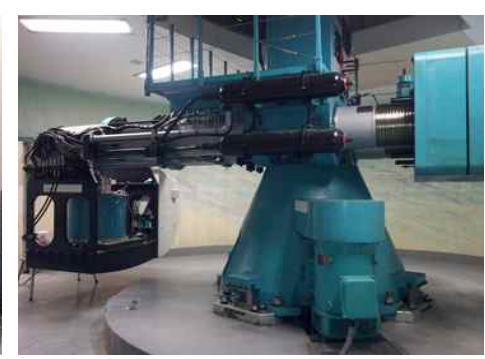

(b)
Fig. 1 Centrifuge load tests: (a) preconsolidation in specimen chamber and (b) centrifuge testing system.

Fig. 1 shows the specimen chamber that was used to prepare clay soil specimens and centrifuge testing system. The centrifuge soil specimens were prepared using kaolinite clay slurry. The specific gravity $\left(G_{s}\right)$, liquid limit (LL), and plasticity index (PI) of the kaolinite were 2.6, 70, and 35, respectively. To form slurry, kaolinite powder and water were mixed with a soil mixer with the application of vacuum condition and fully saturated specimen condition was achieved. Prepared test soils were then moved into the specimen chamber and the preconsolidation pressure was applied. Two preconsolidation pressures of 50 and $300 \mathrm{kPa}$ were used to prepare soft and stiff specimens, respectively. The soil specimen was then moved and assembled into the centrifuge testing system and model foundations were installed within the centrifuge soil specimen. The depth and diameter of the centrifuge soil specimens were 0.4 and $0.9 \mathrm{~m}$ that corresponds to 24 and $54 \mathrm{~m}$ in prototype scale, respectively.

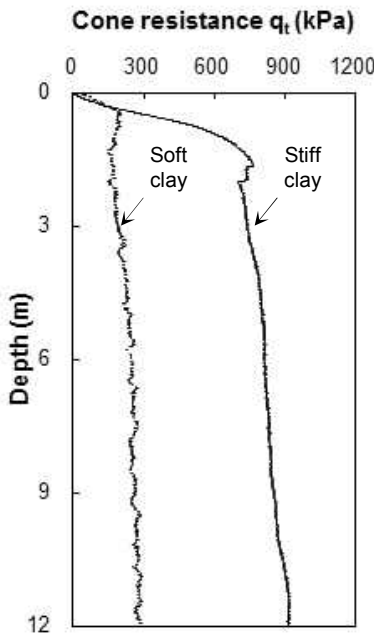

(a)

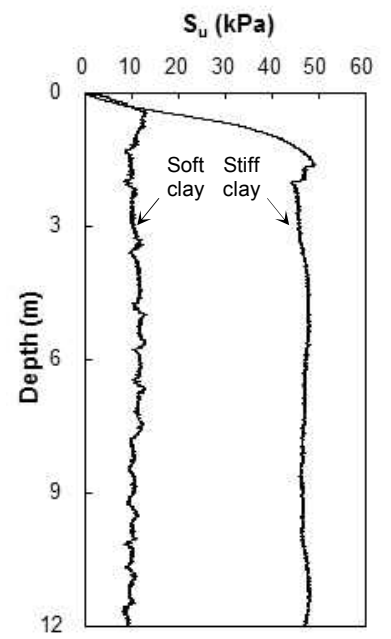

(b)
Fig. 2 Depth profiles of (a) CPT cone resistance and (b) undrained shear strength $\left(s_{u}\right)$ for centrifuge test specimens.

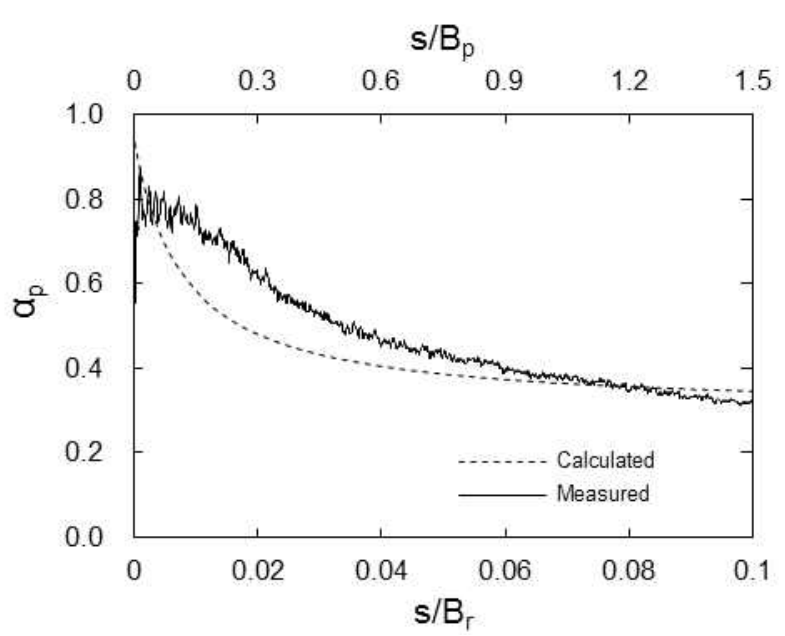

(a)

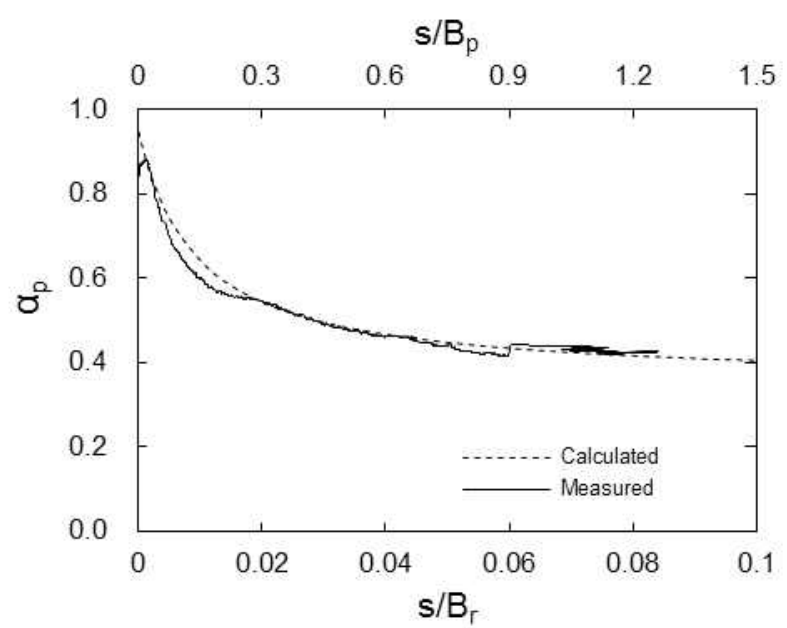

(b)

Fig. 3 Measured and calculated load sharing ratios $\alpha_{p}$ for (a) soft and (b) stiff clays.

The cone penetration tests (CPT) were conducted for the test specimens. Fig. 2(a) shows the depth profiles of cone resistance $\left(q_{t}\right)$ for the test specimens. It is indicated that the clay specimens were fairly homogeneous with limited variation of $q_{t}$ values with depth. Using the CPT results in Fig. 2(a), the undrained shear strengths $\left(\mathrm{s}_{\mathrm{u}}\right)$ were evaluated and plotted in Fig. 2(b). The cone factor $\mathrm{N}_{\mathrm{k}}$ equal to 15 was used in Fig. 2(b). It is seen that the average values of $s_{u}$ were 11 and $46 \mathrm{kPa}$ for soft and stiff conditions, respectively.

\subsection{Measured Load Sharing Behavior}

Using the results from centrifuge tests, measured and calculated values of load sharing ratio $\alpha_{p}$ were obtained and plotted in Fig. 3. For both soft and stiff conditions, $\alpha_{p}$ decreases non-linearly as settlement increases. The value of $\alpha_{p}$ decreases markedly within the initial settlement range, which is thought to be due to the earlier mobilization of pile load capacity. This in turn indicates that the proportion of load carried by piles is greater initially and then decreases with increasing settlement. 
Using the normalized load sharing model of Eq. (7), the values of $\alpha_{p}$ were calculated and compared in Fig. 3. It is seen that the values of $\alpha_{p}$ from the normalized load sharing model match reasonably well the measured load sharing ratios. Some underestimated results were observed from the soft specimen case. The $\mathrm{s} / \mathrm{B}_{\mathrm{r}}=0.035$ and 0.026 correspond to the settlement levels at which the raft load capacity $Q_{r}$ becomes larger than the pile load capacity $Q_{p}$.

\section{CONCLUSIONS}

In this study, a settlement-based load sharing model for piled rafts was described based on the normalized non-linear load-settlement relationship established using the hyperbolic function. It was observed the load sharing ratio $\alpha_{p}$ decreases as settlement increases with rates depending on the load capacity ratio. $\alpha_{p}$ decreases markedly within the initial settlement range, and then decreases moderately as settlement further increases.

The results from centrifuge load tests were presented, which were obtained using different model foundations of unpiled raft, group piles, and piled raft. Different soil conditions of soft and stiff clays were used for the preparation of centrifuge test specimens. The reduction of $\alpha_{p}$ was clearly observed within the initial settlement range due to the earlier mobilization of pile load capacity. The calculated values of $\alpha_{p}$ from the normalized load sharing model showed good agreement with measured values.

\section{ACKNOWLEDGEMENTS}

This work was supported by the National Research Foundation of Korea (NRF) grant funded by the Korea government (MSIP) (No.2011-0030040), and the Ministry of Education (No.2013R1A1A2058863).

\section{REFERENCES}

1) Clancy, P., and Randolph, M. F. Simple design tools for piled raft foundations. Geotechnique 1996; 46(2): 313 - 328.

2) Conte, G., Mandolini, A., and Randolph, M. F. Centrifuge modeling to investigate the performance of piled rafts. Proc. 4th International Geotechnical Seminar on deep foundation on bored and auger Piles, Ghent: Millpress 2003; Van Impe (ed.): 359 - 366.

3) Giretti, D. Modelling of piled raft foundations in sand. Ph.D. Thesis, University of Ferrara, Italy 2010

4) Katzenbach, R., Schmitt, A., and Turek, J. Assessing Settlement of High-Rise Structures by 3D Simulations. Computer-Aided Civil and Infrastructure Engineering 2005; 20(3): 221-229.

5) Kondner, R. L. Hyperbolic stress-strain response: cohesive soils. J. Soil Mech Found Div - ASCE 1963; 89(SM1) : 115-143.

6) Lee, J., and Salgado, R. Determination of pile base resistance in sands. $J$.Geotech. Geoenviron. Eng ASCE 1999; 125(8): 673 - 683 .

7) Lee, J., Park, D., and Choi, K., Analysis of load sharing behavior for piled rafts using normalized load response model; Comput Geotech 2014; 57, 65-74.

8) Randolph, M. F. Design methods for pile groups and piled rafts. Proc. 13th International Conference on Soil Mechanics and Foundation Engineering, New Delhi, India 1994; 5: 61-82.

9) Reul, O., and Randolph, M. F. Design strategies for piled rafts subjected to nonuniform vertical loading. $J$.Geotech. Geoenviron. Eng ASCE 2004; 130(1) :1-13.

10) de Sanctis, L., and Mandolini, A. Bearing capacity of piled rafts on soft clay soils. J .Geotech. Geoenviron. Eng ASCE 2006; 132(12) : 1600-1610. 